\title{
Barriers and facilitators to self-monitoring of blood glucose in people with type 2 diabetes using insulin: a qualitative study
}

This article was published in the following Dove Press journal:

Patient Preference and Adherence

15 February 2014

Number of times this article has been viewed

Woon May Ong'

Siew Siang Chua'

Chirk Jenn $\mathrm{Ng}^{2}$

'Department of Pharmacy, ${ }^{2}$ University of Malaya Primary Care Research Group (UMPCRG), Department of Primary Care Medicine, Faculty of Medicine, University of Malaya, Kuala Lumpur, Malaysia
Correspondence: Siew Siang Chua Department of Pharmacy, Faculty of Medicine, University of Malaya, 50603 Kuala Lumpur, Malaysia

Tel +60379676688

Fax +60379674964

Email chuass@um.edu.my
Background: Self-monitoring of blood glucose (SMBG) helps to improve glycemic control and empowerment of people with diabetes. It is particularly useful for people with diabetes who are using insulin as it facilitates insulin titration and detection of hypoglycemia. Despite this, the uptake of SMBG remains low in many countries, including Malaysia.

Purpose: This study aimed to explore the barriers and facilitators to SMBG, in people with type 2 diabetes using insulin.

Patients and methods: Qualitative methodology was employed to explore participants' experience with SMBG. Semistructured, individual in-depth interviews were conducted on people with type 2 diabetes using insulin who had practiced SMBG, in the primary care clinic of a teaching hospital in Malaysia. Participants were purposively sampled from different age groups, ethnicity, education level, and level of glycemic control (as reflected by the glycated hemoglobin $\left.\left[\mathrm{HbA}_{1 c}\right]\right)$, to achieve maximum variation in sampling. All interviews were conducted using a topic guide and were audio-recorded, transcribed verbatim, checked, and analyzed using a thematic approach.

Results: A total of 15 participants were interviewed, and thematic saturation was reached. The factors that influenced SMBG were mainly related to cost, participants' emotion, and the SMBG process. The barriers identified included: frustration related to high blood glucose reading; perception that SMBG was only for insulin titration; stigma; fear of needles and pain; cost of test strips and needles; inconvenience; unconducive workplace; and lack of motivation, knowledge, and self-efficacy. The facilitators were: experiencing hypoglycemic symptoms; desire to see the effects of dietary changes; desire to please the physician; and family motivation.

Conclusion: Participants' perceptions of the purpose of SMBG, the emotions associated with SMBG, and the complexity, pain, and cost related to SMBG as well as personal and family motivation are the key factors that health care providers must consider when advising people with diabetes on SMBG.

Keywords: blood glucose self-monitoring, diabetes mellitus, in-depth interviews, qualitative study

\section{Introduction}

Self-monitoring of blood glucose (SMBG) is a tool that enhances self-care among people with diabetes. ${ }^{1}$ SMBG improves empowerment in those with diabetes, enabling them to assess the effects of lifestyle changes and medications on their blood glucose levels. ${ }^{2,3}$ Consequently, SMBG allows people with diabetes to undertake the necessary interventions to help improve their health outcomes. ${ }^{3}$ For people with type 2 diabetes using insulin, the benefit of SMBG in improving glycemic control is well established. ${ }^{4}$ 
SMBG helps people with diabetes to detect hypoglycemia and to adjust their insulin dosage appropriately. $1,3,5$

Despite SMBG being highly recommended in people with diabetes using insulin, ${ }^{3,5,6}$ its utilization remains low. Two Australian studies reported that $88.4 \%$ and $81.7 \%$ of those with diabetes using insulin practiced SMBG. ${ }^{7,8}$ Such high prevalence of SMBG use may be attributed to the subsidies for test strips provided by the federal government since 1987. ${ }^{7}$ However, in the United States of America and Italy, it was found that only a minority of those with diabetes using insulin $(26 \%$ and $13.9 \%$, respectively) practiced at least daily SMBG, even though the monitoring devices are provided free in Italy. ${ }^{9,10}$ In Hungary, only $20 \%$ of people with diabetes were found to practice daily SMBG. Those using insulin were reimbursed for SMBG. ${ }^{11}$

In Asian countries, such as Korea, only $32 \%$ of people with type 2 diabetes were shown to practice SMBG regularly, ${ }^{12}$ but in China, $39.5 \%$ of those with type 2 diabetes were shown to practice SMBG at least once monthly. ${ }^{13}$ However, these studies did not specify the utilisation pattern of SMBG among those using insulin.

In Malaysia, it was shown that only $6.9 \%$ and $26.8 \%$ of people with diabetes in private clinics and public hospitals, respectively practiced SMBG. On an average, these people monitored their blood glucose levels about eleven times a month. ${ }^{14,15}$ Another study reported similar findings, with only $15.3 \%$ of people with type 2 diabetes practicing SMBG. ${ }^{16}$ This study also found that the use of insulin was one of the predictors for SMBG, but the utilisation pattern of SMBG among those on insulin was not reported.

Quantitative studies have identified several barriers to the practice of SMBG among people with diabetes. These include advancing age, lower education level and income group, fewer comorbidities, fear of testing and pain, and lack of physician support or visits. ${ }^{10,16,17}$ In addition, a number of qualitative studies have described reasons for SMBG underutilization, such as distressing emotions and thoughts, fingertip pain, discouragement and frustration about "poor" blood glucose reading, lack of awareness of hypoglycemia and hyperglycemia, lack of social support, and difficulty in interpreting SMBG results. ${ }^{18-20}$

Most of the studies either focused on people with type 2 diabetes who were not using insulin, included both people with type 1 and type 2 diabetes, or broadly discussed selfmanagement care but not specifically SMBG. Thus far, there are few studies in Malaysia focusing on the attitudes on SMBG held by people with type 2 diabetes using insulin, the reasons for the adoption or not of SMBG, or on how SMBG is incorporated into the self-management of diabetes. Given the well-established benefits of SMBG among people with type 2 diabetes using insulin and the recommendation for these people to engage in SMBG by both international ${ }^{1,3,5}$ and local ${ }^{6}$ guidelines, a study on this population is of utmost importance.

Therefore, this study aimed to explore the barriers and facilitators to SMBG in people with type 2 diabetes using insulin. Understanding the attitudes and reasons underlying their behavior can provide valuable insights into the rationale for the practice of SMBG and its perceived benefits. This may help health care providers and the authorities concerned to improve the utilization of SMBG in this group of people with type 2 diabetes, who require more stringent glycemic control.

\section{Patients and methods}

A qualitative methodology was employed to explore participants' experience in SMBG. This approach allows the researchers to obtain more in-depth information concerning the participants' attitudes on SMBG. ${ }^{21}$ In this study, individual in-depth interviews were conducted to enable participants to express their personal views and preferences on SMBG more freely. Focus group discussions were not adopted because participants, conscious of how the others present in the group might think of them, might have felt restricted in expressing their opinion freely.

Participants were recruited from a primary care clinic of the University Malaya Medical Centre, an urban teaching hospital in Malaysia. The number of participants recruited was based on data saturation, that is, data collection was stopped when no new theme emerged from the interviews. ${ }^{21}$ People who were eligible for participation included those who were 21 years and above, were diagnosed with type 2 diabetes, were currently using insulin with or without oral hypoglycemic agents, and who had practiced SMBG. People who were diagnosed with type 1 or gestational diabetes, or unable to understand English, Malay or the Chinese dialect Cantonese, were excluded.

Purposive sampling was used whereby the selection of participants was focused on maximum variation sampling in terms of age group, ethnicity, education level, and level of glycemic control, as reflected by the glycated hemoglobin $\left(\mathrm{HbA}_{1 \mathrm{c}}\right)$ level. This sampling method was intended to increase the likelihood that participants interviewed would provide a range of views and experiences in using SMBG. ${ }^{21}$ 
Participants were recruited and interviewed between January and June 2013. A researcher screened patients' medical records before their clinic appointments, and those who met the inclusion criteria were enlisted. On the day of the clinic appointments, those selected were invited to participate in the study. When a person agreed to participate in the study, a Participant Information sheet was given, and the participant signed an informed consent declaration before commencement of the in-depth interview. The participant's demographic and relevant clinical data were obtained and recorded using a data collection form. This study was approved by the Medical Ethics Committee (reference number 956.13) of the University Malaya Medical Centre.

A semistructured interview topic guide (Table 1) was developed based on the literature, conceptual framework (Figure 1), and experts' opinions. Conceptual framework was drawn from the literature while the experts in this study comprised experienced researchers. Most of the questions were open-ended to encourage participants to provide indepth information. Prompts were used only if the participants did not raise the key issues spontaneously.

A pilot study was conducted with two participants to ensure that the questions were clear and relevant. This also helped the researcher to become familiar with the study procedure. The two researchers who conducted the interviews had no prior professional contact with the participants. The pilot study showed that the topic guide was suitable for subsequent interviews. Therefore, the interview procedure and topic guide were maintained with minimal amendment, and the data obtained were included in the analysis.

A total of 24 people with diabetes (including two participants from the pilot study) were approached. The reasons for nonparticipation included no interest $(\mathrm{n}=4)$, language barrier $(n=3)$, and time factor $(n=2)$.

Table I Summary of interview topic guide on barriers and facilitators to SMBG

- How did you start testing your blood sugar at home? Who advised you? Why do you need to do the test?

- Physician, pharmacist, diabetes nurse, family, friends, self

- How often do you test your blood sugar at home?

- What is your physician's recommendation on testing frequency? Do you follow? Why?

- Are there times that you stop testing or test more often? Why? - Sick, travel, fasting, special occasion, work

- What do you understand about your blood sugar reading at home? What do you do with the reading?

- What difficulties or problems did you encounter? How and why?

- What kind of help do you need to overcome these barriers?

Abbreviation: SMBG, self-monitoring of blood glucose.
All the in-depth interviews were carried out by the same researcher, in a private room to ensure confidentiality. ${ }^{21}$ After each interview the researcher reflected and made notes on the interview. This helped to identify any personal biases and experiences that may have influenced the interviews and interpretation of the data. Each interview lasted between 16 and 41 minutes. All interviews were audio-recorded and transcribed verbatim. Four transcripts that were in Cantonese were transcribed and translated by an independent person who was proficient in both Cantonese and English. All transcripts were checked independently for accuracy and then used as data for analysis.

A thematic analysis was carried out through constant comparison across transcripts. The researchers familiarized themselves with the data by reading the transcripts repeatedly to identify key ideas and recurrent codes. ${ }^{21}$ Three researchers coded the first two transcripts independently and created a list of themes. The remaining transcripts were coded by one of the researchers. Any new theme that emerged was added to the list upon consultation with the other researchers; the new codes were then categorized and merged to form larger concepts. The coding was compared for consistency, to minimize any biases as well as to enhance data credibility. Any coding discrepancies were resolved through discussion until consensus was achieved. The data obtained were managed using an open-source, computerassisted qualitative data analysis software, Text Analysis Markup System (TAMS) Analyzer (Matthew Weinstein, University of Washington-Tacoma, Tacoma, WA, USA).

One of the researchers is a family medicine physician and academician; another is an experienced pharmacist and academician. The third researcher is an experienced pharmacist and postgraduate candidate.

\section{Results}

Finally, 15 participants were included in this study. The demographic and clinical background of the participants are presented in Table 2. The list of themes that influenced the practice of SMBG is summarized in Table 3. Participant quotations were cited verbatim, after translation (where appropriate).

\section{Barriers to SMBG}

Participants highlighted a range of perceived barriers to their utilization of SMBG. These included the cost of test strips and needles; frustration related to high blood glucose reading; perception that SMBG was only for insulin titration; stigma; fear of needles and pain; inconvenience; unconducive workplace; lack of motivation; and lack of knowledge and self-efficacy. 


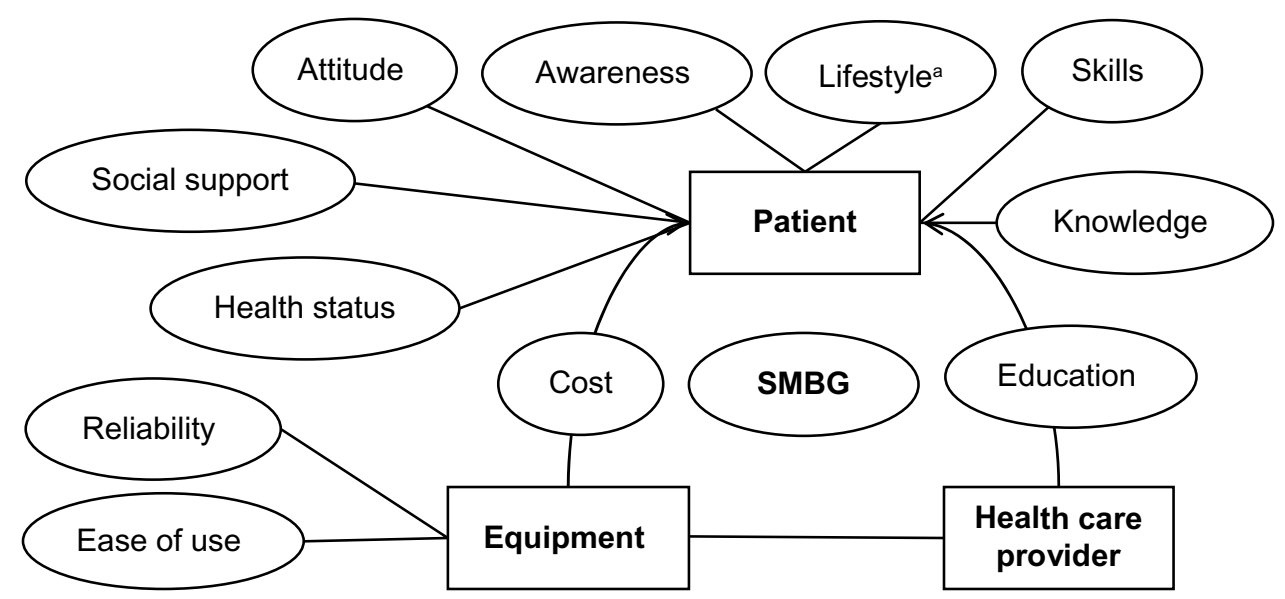

Figure I Conceptual framework of factors influencing the use of SMBG.

Note: aLifestyle includes diet, exercise, travel, fasting and work.

Abbreviation: SMBG, self-monitoring of blood glucose.

\section{Cost of test strips and needles}

The cost for SMBG was the main reason why participants did not practice SMBG regularly.

Because, you know, the strips are very expensive, so I seldom do it like err until she [the daughter] shouted at me

Table 2 Participants' demographic and clinical background

\begin{tabular}{|c|c|}
\hline Characteristics & $\begin{array}{l}\text { Number of } \\
\text { participants (\%) }\end{array}$ \\
\hline $\mathrm{n}$ & 15 \\
\hline Age (years), mean $\pm S D$ (range) & $58.7 \pm 14(23-83)$ \\
\hline \multicolumn{2}{|l|}{ Sex } \\
\hline Male & $8(53)$ \\
\hline Female & $7(47)$ \\
\hline \multicolumn{2}{|l|}{ Ethnicity } \\
\hline Malay & $3(20)$ \\
\hline Chinese & $6(40)$ \\
\hline Indian & $6(40)$ \\
\hline \multicolumn{2}{|l|}{ Marital status } \\
\hline Single & $2(13.3)$ \\
\hline Married & II (73.4) \\
\hline Widower & $2(13.3)$ \\
\hline \multicolumn{2}{|l|}{ Highest level of education } \\
\hline None & I (6.6) \\
\hline Primary school & $2(13.3)$ \\
\hline Secondary school & $7(47)$ \\
\hline Diploma & $3(20)$ \\
\hline Undergraduate degree & I (6.6) \\
\hline Undisclosed* & I (6.6) \\
\hline Duration of diabetes (years), mean \pm SD (range) & $14.1 \pm 7.6(1-30)$ \\
\hline Duration of SMBG, mean \pm SD (range) & $\begin{array}{l}3.4 \pm 2.8 \text { years } \\
(2 \text { months }-10 \text { years })\end{array}$ \\
\hline \multicolumn{2}{|l|}{ 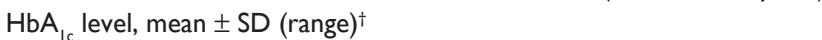 } \\
\hline$\%$ & $8.4 \pm I(6.4-9.6)$ \\
\hline $\mathrm{mmol} / \mathrm{mol}$ & $68.7 \pm 10.7(46-8 I)$ \\
\hline
\end{tabular}

Notes: "Participant refused to disclose the information; 'participants' latest value at the time of interview.

Abbreviations: $\mathrm{HbA}_{1 \mathrm{c}}$, glycated hemoglobin; SD, standard deviation; SMBG, selfmonitoring of blood glucose. one day and said, you know, "What's the point I buy the meter for you and you don't use it?” And I said 'The strips are so expensive," you know, "Where do you want me to get the money?" [P01, 57-year-old female clerk, diabetes for 17 years]

I cannot simply check every day, because err, the thing [test strip] is also expensive. We need to buy the strips, we need to buy the needles, unless if I get it free then it doesn't matter. I don't mind checking it every day [participant laughed]. [P07, 45-year-old male credit officer, diabetes for 4 years]

\section{Frustration related to high blood glucose reading} SMBG can be a very challenging and frustrating task for some participants. High blood glucose readings affected

Table 3 Barriers and facilitators to SMBG by people with type 2 diabetes using insulin

\begin{tabular}{ll}
\hline Barriers & Cost of test strips and needles \\
- Frustration related to high blood glucose \\
reading \\
- Perception that SMBG was only for insulin \\
titration \\
- Stigma \\
- Fear of needles and pain \\
- Inconvenience \\
- Unconducive workplace \\
- Lack of motivation \\
- Lack of knowledge and self-efficacy \\
- Experiencing hypoglycemic symptoms \\
- Desire to see the effects of dietary changes \\
- Desire to please the physician \\
- Family motivation
\end{tabular}

Abbreviation: SMBG, self-monitoring of blood glucose. 
participants negatively, and some might even stop SMBG altogether.

[If] It's a bit 1, 1, 2 [mmol/L] more, I get frustrated. "Why is the blood glucose not coming down." Ahh, that frustration. I pray hundred times, I pray, pray, pray, [that it] must not be more than this, must not be, still I prick and see "Oh, it is more than that," I worked out. Before that sickness kills me, the mental torture will kill me. Ahh, that's why I just couldn't be bothered [to practice SMBG]. [P14, 61-year-old female retiree, diabetes for 20 years]

Participants also stated that they would omit SMBG if they expected their blood glucose levels to be high owing to lack of dietary control.

During December nothing [SMBG not done], I dare not [participant laughed], I dare not check, because I was also eating sweets. I was also having a little bit of wine, how do you test your sugar level [participant laughed], when you drink wine? [P01, 57-year-old female clerk, diabetes for 17 years]

Participants also felt that carrying the glucose meter along when travelling was depressing and hence, tended to leave the meter behind.

December, I seldom check and I was away from the country also for a holiday. So, I let myself go during that time actually, don't want to carry the strip, I mean the testing machine around to, you know to depress myself [participant giggled]. [P01, 57-year-old female clerk, diabetes for 17 years]

\section{Perception that SMBG was only for insulin titration} Participants believed that the main purpose of SMBG was to establish the correct insulin dose. Once the dose was "stabilized," participants were less likely to practice SMBG.

I, I used it [SMBG] for a while then I stopped [participant giggled] because I've achieved, err, my dosage level. For a start, it's [SMBG] helpful but once you have established yourself, your insulin is stabilized, then I think you can just do it less frequently. [P09, 62-year-old male retiree, diabetes for 7 years]

\section{Stigma}

Participants may have perceived the practice of SMBG as a stigma, and hence, they were reluctant to practice SMBG in the presence of other people.
You go travelling and other people can see [participant laughed]. I don't dare to tell other people I have to do all these [SMBG]. I don't dare to tell [participant giggled], not nice to let other people know. [P08, 48-year-old female housewife, diabetes for 1 year]

\section{Fear of needles and pain}

Participants found the fingertip pricking painful and hence did not practice SMBG that frequently.

Once you prick, you will still jump a bit. Whoever says no pain is faking it. If I test every day, my fingers will have many holes, very painful. [P08, 48-year-old female housewife, diabetes for 1 year]

\section{Inconvenience}

Participants felt that SMBG was a cumbersome procedure, and this had impeded their SMBG, even at home. This is probably because they were using the older, bulkier glucose meters.

No, my glucose meter is not user-friendly and it is a bigger thing, is a big box. It affects me, taking it out, putting it back, you see. I need a special place for myself. [P06, 69-year-old female retiree, diabetes for 15 years]

\section{Unconducive workplace}

Workplace that is unconducive also seemed to hinder SMBG.

I work at the workshop. Hands are dirty. I have to run there, run here. I won't do the test at the corner of my workplace. Troublesome. That's the problem. But if I work in the office, everything is possible. I'm afraid my workplace has germs. [P11, 52-year-old male police officer, diabetes for 20 years]

\section{Lack of motivation}

Participants reported that they were "very keen" and "hardworking" in practicing SMBG at the beginning. They did it conscientiously, based on their physicians' or diabetes educators' recommendations. However, they lost their motivation over time.

Beginning yes, beginning very keen, now no. I'm just simply lazy to do it. [P06, 69-year-old female retiree, diabetes for 15 years]

\section{Lack of knowledge and self-efficacy}

Participants often considered frequent SMBG as unnecessary, and this caused them to change the way they monitored 
their blood glucose levels based on their own perceived needs.

When I first started [SMBG], I tried three times a day. Before breakfast, before lunch, before dinner. I feel that it doesn't serve purpose. I practiced this [three times a day] only once. I said to myself, "For what? The blood sugar will surely rise after meals." That's why I only monitor once every morning now. [P13, 62-year-old male retiree, diabetes for 15 years]

Participants felt overwhelmed by the instructions to practice SMBG and had to rely on others to do the SMBG for them.

He [husband] helps me, helps me to test the blood sugar, helps me to inject insulin at night. I can't do it on my own. I don't have the mood to learn. I already have many illnesses [participant laughed]. I need to remind him to test for me. Sometimes I keep thinking, "I don't want to ask him.” I'm very lazy, very lazy and I didn't test. [P12, 71-year-old female housewife, diabetes for 30 years]

\section{Facilitators to SMBG}

Facilitators that encouraged participants to practice SMBG include: experiencing hypoglycemic symptoms; desire to see the effects of dietary changes; desire to please the physician; and family motivation.

\section{Experiencing hypoglycemic symptoms}

Participants cited that they were more likely to practice SMBG when they experienced symptoms, which included tiredness, giddiness, uneasiness, and body ache.

Blood sugar monitoring helps me to control my sugar, you know. Sometimes, when I feel very giddy, I will check my sugar level and when it's high, you know, I control my food. It helps me to control my food and all that. [P03, 55-year-old male administrative officer, diabetes for 5 years]

\section{Desire to see the effects of dietary changes}

Participants reported that they practiced SMBG to check the effects of food on their blood glucose levels.

When I go for buffet lunch and eat a lot of rubbish, I didn't know what I was eating. Then I get scared, I go back, test my sugar [participant laughed]. That's why I tested sometimes. [P06, 69-year-old female retiree, diabetes for 15 years]
Participants reported that they were prompted to practice SMBG to check the effects of new types of food that they had consumed.

Like after you have eaten a certain food, which you have not eaten before. Once eaten then you need to test, the next morning you need to test. To see if the blood sugar level is high. [P04, 83-year-old male retiree, diabetes for 18 years]

\section{Desire to please the physician}

Participants claimed that they would "behave" and practice SMBG according to their physicians' recommendations when their appointment dates were approaching. This is because participants wanted to show their physicians the "good" SMBG results so that their insulin dose could be decreased or they could have a longer interval before their next appointment.

I have been using it [SMBG] every day because I know

I have got an appointment coming up, so I better behave [participant giggled]. So that I can tell the doctor, you know, I want to bring down the insulin dose. [P01, 57-year-old female clerk, diabetes for 17 years]

\section{Family motivation}

Support from family members motivated participants to practice SMBG.

My daughter used to make noise. "Do you know what's your sugar level?" I said "How am I supposed to know? I don't have a meter to test." [participant giggled]. That's why she purchased it for me. [P01, 57-year-old female clerk, diabetes for 17 years]

\section{Discussion}

\section{Main findings and comparisons with other studies}

Most participants perceived cost as the most important barrier to SMBG, a finding similar to that of other studies. ${ }^{12,22,23} \mathrm{In}$ Malaysia, there are no subsidies for test strips and needles. ${ }^{24}$ Even when test strips were reimbursed in the United States of America, people with diabetes still reported that SMBG was costly. ${ }^{18}$ Higher costs have been associated with poor adherence to SMBG. ${ }^{25,26}$ It has been reported that the costs associated with diabetes complications, ${ }^{27,28}$ and the number and overall duration of hospitalizations ${ }^{29}$ for people with diabetes were significantly reduced among SMBG users compared with non-SMBG users. Therefore, an increase in 
SMBG utilization among insulin users, besides improving glycemic control, would help to save some health care costs in the long-term. Subsidies for test strips and needles would help to ease the financial burden for people with diabetes, and this would increase their adherence to SMBG. ${ }^{30}$

Obtaining higher than normal blood glucose readings elicited feelings of frustration and discouragement, leading to decreased motivation among people with diabetes and nonadherence to SMBG. ${ }^{31}$ Likewise, negative thoughts that were shown to interfere with SMBG include not wanting to know the results when the blood glucose levels were likely to be high. ${ }^{18,32}$ Such thoughts may lead to denial or indifference, when those with diabetes interpret high blood glucose readings as poor control. ${ }^{19}$ These findings suggest that interventions by health care providers are required to help people with diabetes cope with negative feelings and to prevent these from influencing their decision to practice SMBG.

The perception that SMBG is solely for insulin titration could be a concern. Therefore, it is recommended that health care providers improve awareness in people with diabetes through appropriate education regarding the other benefits of SMBG in diabetes control. Group diabetes education should be considered as this has been shown to increase adherence to $\mathrm{SMBG}^{7}$

People with diabetes have reported that stigma is a significant concern to them. ${ }^{33}$ This probably causes tension and anxiety, leading to suboptimal SMBG. Another study found that some people discriminated against people with diabetes who injected insulin in public, equating them to addicts or users of illegal drugs. People with diabetes who were recipients of discrimination tended to omit SMBG and delayed their insulin injections. ${ }^{34}$ This fear of practicing SMBG in front of other people could be minimized via education and support, through counseling and peer support groups, which may help to reduce the emotional impact of stigma and enhance coping. ${ }^{33}$

Although the needles used for SMBG nowadays are relatively fine, ${ }^{35}$ anxieties over the use of needles and pain may still occur and lead to decreased adherence to SMBG. ${ }^{30,36}$ Health care providers have to consider these factors when discussing SMBG with people with diabetes - they should be taught techniques for making the finger prick less painful, for instance, using the lateral side of the finger, avoiding use of the thumbs and index fingers, or using shallower needle depths ${ }^{2}$ in addition, alternative-site testing such as the arm, abdomen, and thigh may be used to give the fingers a rest. ${ }^{1,35}$ People with diabetes should also be counseled on the correct interpretation of their SMBG results.
The finding that SMBG was inconvenient is consistent with other studies that also described SMBG procedure as inconvenient and difficult, leading to poor adherence to SMBG. ${ }^{2,25,26}$ However, with the advancement of technology, the testing process has been greatly improved and simplified, hence, more convenient to manage. ${ }^{37}$

Some participants perceived their workplace as unsuitable for SMBG and found it troublesome to practice SMBG outside their homes. This finding is in accordance with that of another study. ${ }^{25}$ This barrier could be resolved by educating people with diabetes regarding suitable areas and times for practicing SMBG. A clean room is not necessary for practicing SMBG, but the person must be able to clean their hands properly before pricking their own fingers. The benefits of regular SMBG should be emphasized as studies have shown improvement in adherence to SMBG through education and self-management training. ${ }^{7,19}$

Self-motivation facilitated the practice of SMBG for participants in this study, but they were not able to sustain such motivation. Some participants attributed this to laziness. This finding corresponds to that of other studies. ${ }^{36,38}$ Simple diabetes education has been found to be sufficiently motivational and to improve the frequency of SMBG. ${ }^{7,36}$ Thus, health care providers can reinforce the commitment of those with diabetes to conduct SMBG by discussing their SMBG results so that they are keen to practice SMBG to monitor their glycemic control.

Most participants in this study were educated (secondary school and higher). Education might have influenced their understanding and knowledge of the importance of SMBG. It was suggested that people with diabetes who were less informed about their disease and plan of care would be less likely to practice SMBG. ${ }^{12,38,39}$ On the other hand, those with diabetes who received information about SMBG felt empowered. ${ }^{18,19}$ It was shown that an empowerment-based diabetes self-management support intervention, consisting of weekly educational newsletters coupled with clinical feedback from the health care providers, significantly improved the practice of SMBG. ${ }^{40}$ Close follow-up by health care providers may also help to enhance adherence to SMBG. ${ }^{1}$

Studies have shown that people with diabetes who experienced hypoglycemic events were more likely to practice SMBG to confirm their symptoms so that appropriate actions could be taken. ${ }^{18,36,41}$ Most participants in this study assumed that dizziness is a hypoglycemic symptom, but dizziness may indicate episodes of hypoglycemia or hyperglycemia. ${ }^{1}$ It is possible that the episodes of both conditions may be identified incorrectly, leading to unnecessary fear or wrong action 
being taken. Therefore, health care providers should provide clear explanations of how SMBG could help in determining the cause of dizziness (as opposed to basing this on mere conjecture).

Intake of large amounts of food or foods that were perceived as "new" to participants prompted them to monitor their blood glucose levels. This is consistent with a previous study, in which people with diabetes practiced SMBG more often during dinner gatherings and festivities. ${ }^{39}$ This indicates that SMBG may help those with diabetes to understand the cause-and-effect relationship between food and blood glucose levels, thus affirming one of the uses of SMBG stated in the guidelines, that is, the results of SMBG can be useful in adjusting dietary intake.,

The health care providers' attention in responding to the blood glucose readings was one of the reasons some participants gave for continuing SMBG. This, in turn, created participants' interest in SMBG so that they could anticipate positive feedback on their glycemic control from their physicians. It was found that the lack of interest of health care providers in the United Kingdom contributed to a decrease in $\mathrm{SMBG} .{ }^{20}$ Therefore, health care providers should discuss the SMBG results with those concerned, to encourage optimal use of SMBG. It has been suggested that continuous guidance and routine follow-up evaluation, of SMBG technique and of the ability of people with diabetes to respond to their readings appropriately, should be implemented. ${ }^{3}$

The finding of family motivation as a facilitator to SMBG practice was similar to that of other studies that found those with family support were more likely to practice SMBG. ${ }^{12,19,22,23}$ Encouragement and assistance from a family member or friend would foster more positive attitudes toward SMBG. ${ }^{19}$ Therefore, support, whether received emotionally or financially, empowers people with diabetes to be active in their self-care. Health care providers should facilitate support networks through empowerment interventions, ${ }^{40}$ to optimize SMBG use.

\section{Strengths and limitations}

The sample comprised participants with a broad range of perspectives on SMBG. Thus, the researchers were able to gain an in-depth understanding of the experiences of people from different demographic backgrounds. Such information can ensure that the barriers to SMBG can be addressed before, during, and even after SMBG initiation; further, the facilitators to SMBG can be employed during counseling, for enhancing empowerment in those with diabetes. The results of this study were based on self-reporting by participants who had practiced SMBG. The views of people with diabetes using insulin who had never practiced SMBG were not explored. Future studies should explore the reasons for not practicing SMBG. This study was conducted in an urban teaching hospital in Malaysia, where participants have easy access to health care facilities. Therefore, the study findings may not be applicable to other settings where health care services are more limited. In addition, health care providers' perceptions on SMBG should be explored in future studies. A quantitative approach with a large-scale survey, to determine how common the barriers or facilitators to SMBG are identified in the present study, would be required for the purpose of generalization.

\section{Conclusion}

The main benefit of SMBG is to help people with diabetes improve their glycemic control. In order to enhance adherence to $\mathrm{SMBG}$, the barriers and facilitators to SMBG were explored through their perspectives. The findings of this study show that SMBG was practiced primarily to confirm symptoms and the effects of food intake rather than on a routine basis. Cost was a common barrier to SMBG. Health authorities concerned should consider providing financial incentives to encourage more frequent monitoring of blood glucose levels. Participants' perceptions of the purpose of SMBG, the emotions associated with SMBG, the complexity and pain related to $\mathrm{SMBG}$, as well as personal and family motivation were the other key factors that health care providers must consider when advising people with diabetes to conduct SMBG.

\section{Acknowledgments}

We would like to express our greatest appreciation to the following for their help: all the participants of this study for agreeing to take time to answer the questions during the interviews; the staff of the primary care family clinic at the University Malaya Medical Centre, Malaysia for their assistance and cooperation; and the University of Malaya, Malaysia for funding this project (reference: PG138-2012B).

\section{Disclosure}

The authors report no conflicts of interest in this work.

\section{References}

1. Canadian Diabetes Association. 2008 Clinical practice guidelines for the prevention and management of diabetes in Canada. Can J Diabetes. 2008;32 Supp1 1:S1-S215.

2. Renard E. Monitoring glycemic control: the importance of self-monitoring of blood glucose. Am J Med. 2005;118(Suppl 9A):S12-S19. 
3. American Diabetes Association. Standards of medical care in diabetes 2013. Diabetes Care. 2013;36 Suppl 1:S11-S66.

4. Canadian Optimal Medication Prescribing and Utilization Service (COMPUS). Systematic review of use of blood glucose test strips for the management of diabetes mellitus. Ottawa, Canada: Canadian Agency for Drugs and Technologies in Health (CADTH). May 2009.

5. Scottish Intercollegiate Guidelines Network. Management of Diabetes. A National Clinical Guideline [116]. Edinburg: Scottish Intercollegiate Guidelines Network; 2010. Available from: http://www.sign.ac.uk/pdf/ sign116.pdf/. Accessed November 12, 2013.

6. Ministry of Health Malaysia. Clinical Practice Guidelines: Management of Type 2 Diabetes Mellitus. 4th ed. Kuala Lumpur: Ministry of Health Malaysia; 2009.

7. Bruce DG, Davis WA, Cull CA, Davis TM. Diabetes education and knowledge in patients with type 2 diabetes from the community: the Fremantle Diabetes Study. J Diabetes Complications. 2003;17(2):82-89.

8. Chubb SA, Van Minnen K, Davis WA, Bruce DG, Davis TM. The relationship between self-monitoring of blood glucose results and glycated haemoglobin in type 2 diabetes: the fremantle diabetes study. Diabetes Res Clin Pract. 2011;94(3):371-376.

9. Harris MI, Cowie CC, Howie LJ. Self-monitoring of blood glucose by adults with diabetes in the United States population. Diabetes Care. 1993;16(8):1116-1123.

10. Scorpiglione N, el-Shazly M, Abdel-Fattah M, et al. Epidemiology and determinants of blood glucose self-monitoring in clinical practice. Diabetes Res Clin Pract. 1996;34(2):115-125.

11. Hankó B, Kázmér M, Kumli P, et al. Self-reported medication and lifestyle adherence in Hungarian patients with Type 2 diabetes. Pharm World Sci. 2007;29(2):58-66.

12. Park H, Hong Y, Lee H, Ha E, Sung Y. Individuals with type 2 diabetes and depressive symptoms exhibited lower adherence with self-care. J Clin Epidemiol. 2004;57(9):978-984.

13. Bi Y, Zhu D, Cheng J, et al. The status of glycemic control: A crosssectional study of outpatients with type 2 diabetes mellitus across primary, secondary, and tertiary hospitals in the Jiangsu province of China. Clin Ther. 2010;32(5):973-983.

14. Mafauzy M. Diabetes control and complications in private primary healthcare in Malaysia. Med J Malaysia. 2005;60(2):212-217.

15. Mafauzy M. Diabetes control and complications in public hospitals in Malaysia. Med J Malaysia. 2006;61(4):477-483.

16. Mastura I, Mimi O, Piterman L, Teng CL, Wijesinha S. Self-monitoring of blood glucose among diabetes patients attending government health clinics. Med J Malaysia. 2007;62(2):147-151.

17. Snoek FJ, Malanda UL, de Wit M. Self-monitoring of blood glucose: psychological barriers and benefits. Eur Diabetes Nurs. 2008;5(3): $112-115$.

18. Hortensius J, Kars MC, Wierenga WS, Kleefstra N, Bilo HJ, van der Bijl JJ. Perspectives of patients with type 1 or insulin-treated type 2 diabetes on self-monitoring of blood glucose: a qualitative study. $B M C$ Public Health. 2012;12:167-177.

19. Nagelkerk J, Reick K, Meengs L. Perceived barriers and effective strategies to diabetes self-management. $J A d v$ Nurs. 2006;54(2):151-158.

20. Peel E, Douglas M, Lawton J. Self monitoring of blood glucose in type 2 diabetes: longitudinal qualitative study of patients' perspectives. $B M J$. 2007;335(7618):493-496.

21. Green J, Thorogood N. Qualitative Methods for Health Research. 2nd ed. London: SAGE Publications Ltd; 2009.

22. Vincze G, Barner JC, Lopez D. Factors associated with adherence to self-monitoring of blood glucose among persons with diabetes. Diabetes Educ. 2004;30(1):112-125.

23. Zgibor JC, Simmons D. Barriers to blood glucose monitoring in a multiethnic community. Diabetes Care. 2002;25(10):1772-1777.
24. treasury.gov.my [homepage on the Internet]. Perkhidmatan di perbendaharaan: 42000 - Pemberian dalam negeri. [Treasury's Services: 42000 - Funds for Internal Affairs]. Ministry of Finance Malaysia; 2010 [updated December 2, 2013; cited November 12, 2013]. Available from: http://www.treasury.gov.my/index.php?option=com_content\&view=ar ticle\&id=1041\&Itemid=167\&lang=my/. Accessed December 28, 2013. Bahasa Melayu.

25. Jones PM, Remley C, Engberg RA. Development and testing of the barriers to self-monitoring blood glucose scale. Diabetes Educ. 1996;22(6):609-616.

26. Kirk JK, Graves DE, Bell RA, Hildebrandt CA, Narayan KM. Racial and ethnic disparities in self-monitoring of blood glucose among US adults: a qualitative review. Ethn Dis. 2007;17(1):135-142.

27. Neeser K, Weber C. Cost impact of self-measurement of blood glucose on complications of type 2 diabetes: the Spanish perspective. Diabetes Technol Ther. 2009;11(8):509-516.

28. Palmer AJ, Dinneen S, Gavin JR, Gray A, Herman WH, Karter AJ. Cost-utility analysis in a UK setting of self-monitoring of blood glucose in patients with type 2 diabetes. Curr Med Res Opin. 2006;22(5): 861-872.

29. Giaccari A, Grassi G, Ozzello A. Self-monitoring of blood glucose: guideline application rather than utilization restrictions on testing strips has potential to reduce diabetes healthcare costs in Italy. Diabetes Technol Ther. 2012;14(10):862-867.

30. Nyomba BL, Berard L, Murphy LJ. The cost of self-monitoring of blood glucose is an important factor limiting glycemic control in diabetic patients. Diabetes Care. 2002;25(7):1244-1245.

31. Holmström IM, Rosenqvist U. Misunderstandings about illness and treatment among patients with type 2 diabetes. $J$ Adv Nurs. 2005;49(2):146-154.

32. Egede LE, Osborn CY. Role of motivation in the relationship between depression, self-care, and glycemic control in adults with type 2 diabetes. Diabetes Educ. 2010;36(2):276-283.

33. Schabert J, Browne JL, Mosely K, Speight J. Social stigma in diabetes: a framework to understand a growing problem for an increasing epidemic. Patient. 2013;6(1):1-10.

34. Tak-Ying Shiu A, Kwan JJ, Wong RY. Social stigma as a barrier to diabetes self-management: implications for multi-level interventions. J Clin Nurs. 2003;12(1):149-150.

35. Heinemann L, Koschinsky T. Clinical application and challenges of blood glucose measurement technology for self-monitoring. Diabetes Technol Ther. 2008;10(Suppl 1):S27-S34.

36. Davis WA, Bruce DG, Davis TM. Is self-monitoring of blood glucose appropriate for all type 2 diabetic patients? The Fremantle Diabetes Study. Diabetes Care. 2006;29(8):1764-1770.

37. Hughes MD. The business of self-monitoring of blood glucose: a market profile. J Diabetes Sci Technol. 2009;3(5):1219-1223.

38. Collins MM, Bradley CP, O’Sullivan T, Perry IJ. Self-care coping strategies in people with diabetes: a qualitative exploratory study. $B M C$ Endocr Disord. 2009;9:6.

39. de Weerdt I, Visser AP, Kok G, van der Veen EA. Determinants of active self-care behaviour of insulin treated patients with diabetes: implications for diabetes education. Soc Sci Med. 1990;30(5):605-615.

40. Tang TS, Funnell MM, Noorulla S, Oh M, Brown MB. Sustaining short-term improvements over the long-term: results from a 2-year diabetes self-management support (DSMS) intervention. Diabetes Res Clin Pract. 2012;95(1):85-92.

41. Farmer A, Balman E, Gadsby R, et al. Frequency of self-monitoring of blood glucose in patients with type 2 diabetes: association with hypoglycaemic events. Curr Med Res Opin. 2008;24(11): 3097-3104. 


\section{Publish your work in this journal}

Patient Preference and Adherence is an international, peer-reviewed, open access journal focusing on the growing importance of patient preference and adherence throughout the therapeutic continuum. Patient satisfaction, acceptability, quality of life, compliance, persistence and their role in developing new therapeutic modalities and compounds to

optimize clinical outcomes for existing disease states are major areas of interest. This journal has been accepted for indexing on PubMed Central. The manuscript management system is completely online and includes a very quick and fair peer-review system. Visit http://www.dovepress.com/ testimonials.php to read real quotes from published authors.

Submit your manuscript here: http://www.dovepress.com/patient-preference-and-adherence-journal 